\title{
Retraction Note to: Tuberous sclerosis with pulmonary lymphangioleiomyomatosis and renal angiomyolipomas. Computed tomographic findings: a case report
}

Flávia G Vianna, Edson Marchiori*, Gláucia Zanetti, Claudia M Mano, Branca Sarcinelli-Luz, Juliana F Carvalho, Carla Assed, Isabella G Santos, Alair ASMD Santos and Alberto D Vianna

\section{Retraction note}

This article [1] has been retracted by the publisher because it was republished in the journal [2] due to an error during transfer of the journal between publishers in 2009. BioMed Central apologizes to the authors and readers for this error and for any inconvenience caused.

\footnotetext{
References

1. Vianna FG, Marchiori E, Zanetti G, Mano CM, Sarcinelli-Luz B, Carvalho JF, Assed C, Santos IG, Santos AA, Vianna AD. Tuberous sclerosis with pulmonary lymphangioleiomyomatosis and renal angiomyolipomas. Computed tomographic findings: a case report. Cases J. 2009;2:9124.

2. Vianna FG, Marchiori E, Zanetti G, Mano CM, Sarcinelli-Luz B, Carvalho JF, Assed C, Santos IG, Santos AA, Vianna AD. Computed tomographic findings of tuberous sclerosis with pulmonary lymphangioleiomyomatosis and renal angiomyolipomas: a case report. Cases J. 2009;2:9238.
}

* Correspondence: edmarchiori@gmail.com

Department of Radiology, Faculty of Medicine, Fluminense Federal University, Rio de Janeiro, Brazil 